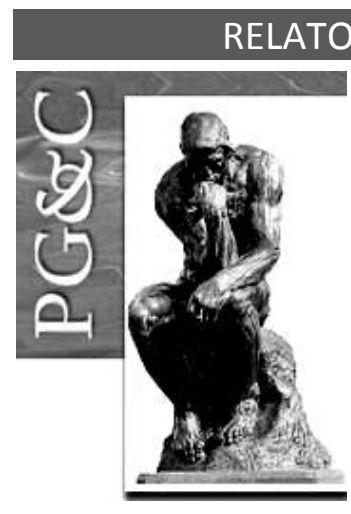

\title{
A GESTÃO DO CONHECIMENTO NA INDÚSTRIA DA MODA: UM ESTUDO EXPLORATÓRIO DA INTER-RELAÇÃO DO MÉTODO PROJETUAL DE DESIGN COM O CICLO DE MEYER E ZACK
}

\author{
Cibelle Akemi Vallim Fernandes \\ Mestre em Gestão do Conhecimento pelo Centro Universitário Cesumar \\ Brasil. Professora do Centro Universitário Cesumar, Brasil. \\ E-mail: cibellevallim@gmail.com \\ Rejane Sartori \\ Doutora em Engenharia e Gestão do Conhecimento pela Universidade \\ Federal de Santa Catarina, Brasil. Professora do Centro Universitário \\ Cesumar, Brasil. \\ E-mail: rejane.sartori@unicesumar.edu.br
}

Nelson Tenório

Doutor em Ciência da Computação pela Pontifícia Universidade Católica do Rio Grande do Sul, Brasil. Professor do Centro Universitário Cesumar, Brasil.

E-mail: nelson.tenorio@unicesumar.edu.br

\begin{abstract}
Resumo
$\mathrm{Na}$ indústria da moda o design é considerado um projeto proveniente da geração de ideias, as quais conduzem a um método projetual de configuração de objetos pensados desde o momento de elaboração até sua aplicação no mercado. Por sua vez, a Gestão do Conhecimento, por meio de seus ciclos, contribui com a melhoria dos processos no intuito de transformá-los em valores competitivos para as organizações, contribuindo para a sistematização do desenvolvimento de produtos na indústria da moda. Nesse sentido, o objetivo desta pesquisa é estabelecer inter-relações entre o método projetual para design com as fases do ciclo da Gestão do Conhecimento de Meyer e Zack. Portanto, esta é uma pesquisa qualitativa e exploratória realizada por meio de levantamento bibliográfico. Os resultados revelam que ao estabelecer inter-relações entre o método projetual e os ciclos da Gestão do Conhecimento de Meyer e Zack, percebe-se que esse método é um agente da Gestão do Conhecimento capaz de capturar, criar, codificar, compartilhar conhecimento. Além disso, essa inter-relação possibilita à organização obter inovação, podendo assim contribuir para o desenvolvimento de produtos a alinhados às expectativas dos clientes.
\end{abstract}

Palavras-chave: Gestão do conhecimento. Métodos para design de moda. Ciclo de Meyer e Zack.

\section{INTERRELATIONSHIPS BETWEEN THE PROJETUAL METHOD FOR FASHION DESIGN AND THE STAGES OF THE KNOWLEDGE MANAGEMENT CYCLE OF MEYER AND ZACK}

\begin{abstract}
In the fashion industry, the design is considered a project which arises from ideas that leads a design method of configuring objects thought during the product elaboration to its market release. As follows, Knowledge Management cycles contribute to processes improvement in order to transform them into competitive values for organizations. Thus, that cycles also systematize the product development within the fashion industry. In this sense, this paper aims to establish interrelations between the design method
\end{abstract}

Perspectivas em Gestão \& Conhecimento, João Pessoa, v. 9, n. 1, p. 154-168, jan./abr. 2019. DOI: http://dx.doi.org/10.21714/2236-417X2019v9n1p154

http://periodicos.ufpb.br/ojs2/index.php/pgc. ISSN: 2236-417X. Publicação sob Licença (cc) EY-NC-ND 
proposed by Montemezzo and the phases of the Knowledge Management cycle suggested by Meyer and Zack. To do that, we performed qualitative and exploratory research, based on a bibliographical review. Our results show that the relationship between design method and Knowledge Management cycle can become a powerful tool capable of capturing, creating, coding, and sharing knowledge to contribute of developing products with greater align concerning customer expectations and gain products' innovation.

Keywords: Knowledge management. Methods for fashion design. Cycle of Meyer and Zack.

\section{INTRODUÇÃO}

A indústria da moda tem sofrido sérias dificuldades em se manter no mercado com as transformações decorrentes da economia globalizada. A entrada dos produtos chineses e os altos impostos são alguns dos motivos que têm tornado difícil a sobrevivência do setor no Brasil, impondo aos empresários o investimento em design de produto, marketing, processos produtivos e equipes de vendas. Dados da Associação Brasileira da Indústria Têxtil (ABIT) revelam que, mesmo com esse quadro desfavorável, essa indústria representa, no contexto nacional, uma das principais atividades econômicas geradoras de emprego e renda, tornando evidente a sua importância (ABIT, 2016).

Essa é uma indústria que demanda dinamismo, criatividade e agilidade no desenvolvimento de produtos em curto prazo de tempo. Isso se deve ao mercado fast fashion, um fenômeno que apresenta novos produtos de vestuário em ciclos muito curtos de desenvolvimento e produção. Há assim a necessidade de desenvolvimento de produtos cada vez mais efêmeros e com uma forte pressão sobre os seus criadores, os designers (WATSON; YAN, 2013).

Na indústria da moda, o desenvolvimento de produtos, também chamado de design, é considerado um projeto proveniente da geração de ideias, em que essas dependem de conhecimento prévio dos indivíduos. De acordo com Nicchelle (2011), é por meio do design que o mundo da moda busca atender as necessidades e os desejos dos consumidores. Assim, 0 design é composto de processos complexos que envolvem diferentes ações, pessoas e setores. O setor responsável pelo design deve organizar as suas atividades para estruturar as ideias e o conhecimento existente. É nesse contexto que Nicchelle (2011) e Montemezzo (2003) sustentam a importância da adoção e uso do método projetual de design, um método para o desenvolvimento de projetos voltado à indústria da moda. Assim, essa indústria aprimora o seu planejamento, pois evidencia a atividade de projetar.

Para Oliveira, Oliveira e Lima (2016) os modelos de ciclos da Gestão do Conhecimento (GC) consistem na sistematização e utilização do conhecimento organizacional. Nesse sentido, Dalkir (2011) ressalta que vários modelos de ciclos da GC contribuem com a melhoria dos processos no intuito de transformá-los em valores competitivos para as organizações. Os ciclos compreendem processos relacionados à captura, aquisição e internalização do conhecimento que contribuem para a sua criação, codificação, disseminação e apropriação. Assim, os ciclos de GC podem apoiar os designers a organizar as suas atividades para estruturar suas ideias no momento do desenvolvimento de novos produtos.

Dentre a diversidade de ciclos da GC presentes na literatura há destaque para o ciclo de Meyer e Zack (1996), que tem como referência um modelo sobre a concepção e o desenvolvimento de produtos de informação. Tal ciclo é específico para o design de produtos e sugere que o seu conhecimento seja transferido para o domínio intelectual servindo de base para um ciclo da GC a ser utilizado nos processos e ações da organização. As fases envolvidas nesse ciclo compreendem a aquisição de dados ou informações, refinamento, armazenamento ou recuperação, distribuição e apresentação ou utilização.

Perspectivas em Gestão \& Conhecimento, João Pessoa, v. 9, n. 1, p. 154-168, jan./abr. 2019. 
Os estudos envolvendo métodos de projeto com enfoque no cliente ainda são relativamente insuficientes, especialmente na indústria da moda. Assim, considerando que todo conhecimento ativo encontra-se nas pessoas e não nas organizações e, ainda, devendo ser esse conhecimento compartilhado de forma explícita e eficaz, conforme considera Dalkir (2011), esta pesquisa tem o objetivo de estabelecer uma inter-relação entre o método projetual de design e o ciclo da GC de Meyer e Zack (1996), contribuindo para que a ciência acerca da indústria da moda evolua no sentido de oferecer a essa indústria dinamismo, criatividade e agilidade desejada para o desenvolvimento de seus produtos.

Este artigo encontra-se estruturado em cinco seções, sendo que após esta introdução apresenta-se o percurso teórico relativo a conhecimento, GC e ciclos da GC, bem como sobre a indústria da moda e os métodos de design de moda. Na terceira seção relata-se a metodologia utilizada nesta pesquisa. Na quarta expõem-se as inter-relações entre o método projetual de design e o ciclo da GC de Meyer e Zack. Por fim, são apresentadas as conclusões, seguidas das referências utilizadas.

\section{PERCURSO TEÓRICO}

\subsection{Conhecimento e gestão do conhecimento}

O conhecimento é uma estrutura intangível que resulta da atividade humana e quando agregado às organizações, constitui o seu capital intelectual. Trata-se de um bem central que impacta diretamente no sucesso da corporação. A importância da criação do conhecimento organizacional é defendida por Trierveiler, Sell e Pacheco (2015). Trata-se da capacidade de uma empresa de criar novo conhecimento e difundi-lo, incorporando-o a serviços, produtos e sistemas. Os autores reforçam que a troca de informação gera novo conhecimento. Isso traz um novo olhar para a necessidade de uma estruturação melhorada do conhecimento para que este possa ser disseminado, proporcionando a inovação constante e o aperfeiçoamento dos produtos e serviços ofertados pela organização.

Costanzo e Sanchez (2014) tipificam o conhecimento em tácito e explícito e ainda apontam as diferenças entre eles. Para os autores, o conhecimento tácito é aquele em que os indivíduos possuem dificuldades em articular e transpor aos outros com clareza. Além disso, ele é adquirido por meio de experiências anteriores. Já o conhecimento explícito é aquele que o indivíduo consegue transpor com facilidade, podendo ser disponibilizado em manuais, arquivos e outros meios, mas, por sua vez, é apenas uma pequena fração do conjunto do conhecimento total.

A grande valia do conhecimento tácito para as empresas e a necessidade da conversão desse conhecimento em explícito é denominada por Nonaka e Takeuchi (1997) como Espiral do Conhecimento, a qual consiste em basicamente quatro etapas de conversão do conhecimento: socialização, externalização, combinação e internalização, como mostrado na Figura 1.

Para Nonaka e Takeuchi (1997), a primeira etapa da Espiral do Conhecimento é a socialização, que acontece basicamente pelas trocas de experiências por meio da observação, da imitação, dos modelos mentais. Normalmente, um trabalhador aprende ao observar 0 outro a executar seu ofício, o que exige confiança e convivência. Esse conhecimento dá-se no nível tácito. A segunda etapa é a externalização, a qual acontece com a conversão do conhecimento tácito em explícito, codificado por meio de livros, manuais, internet, tornandose então explícito para que outras pessoas o entendam. É um processo que se expressa basicamente por meio da linguagem escrita. A terceira etapa refere-se à combinação, que se trata de um processo ordenado de conceitos em um sistema de conhecimento. Os conhecimentos explícitos combinados geram um novo conhecimento para que possa, então,

Perspectivas em Gestão \& Conhecimento, João Pessoa, v. 9, n. 1, p. 154-168, jan./abr. 2019. 
ser multiplicado. Esse modo de conversão ocorre em eventos de educação formal e por meio das redes de conhecimento codificadas, isto é, as intranets existentes nas organizações. Por fim, a quarta etapa diz respeito à internalização, que consiste no processo de incorporação, ou seja, quando o colaborador internaliza o conhecimento que o leva a um novo conhecimento, ocorrendo a reconfiguração do próprio conhecimento tácito e gerando mudanças e melhorias das práticas individuais e coletivas. Esse conhecimento dá-se do nível explícito para o tácito.

Utilizar os ativos de conhecimento da empresa e transformá-los efetivamente em vantagem competitiva no mercado é o grande desafio da GC. Ela tem se destacado nas organizações como forma de questionar o modelo tradicional de gestão vigente. Tal modelo, na atualidade, não atende à demanda por mobilidade premente nas organizações, principalmente pela evidência de uma nova forma de diferencial competitivo centrado no ser humano (FREIRE; SOUZA; PEREIRA, 2015).

Figura 1 - Espiral do conhecimento

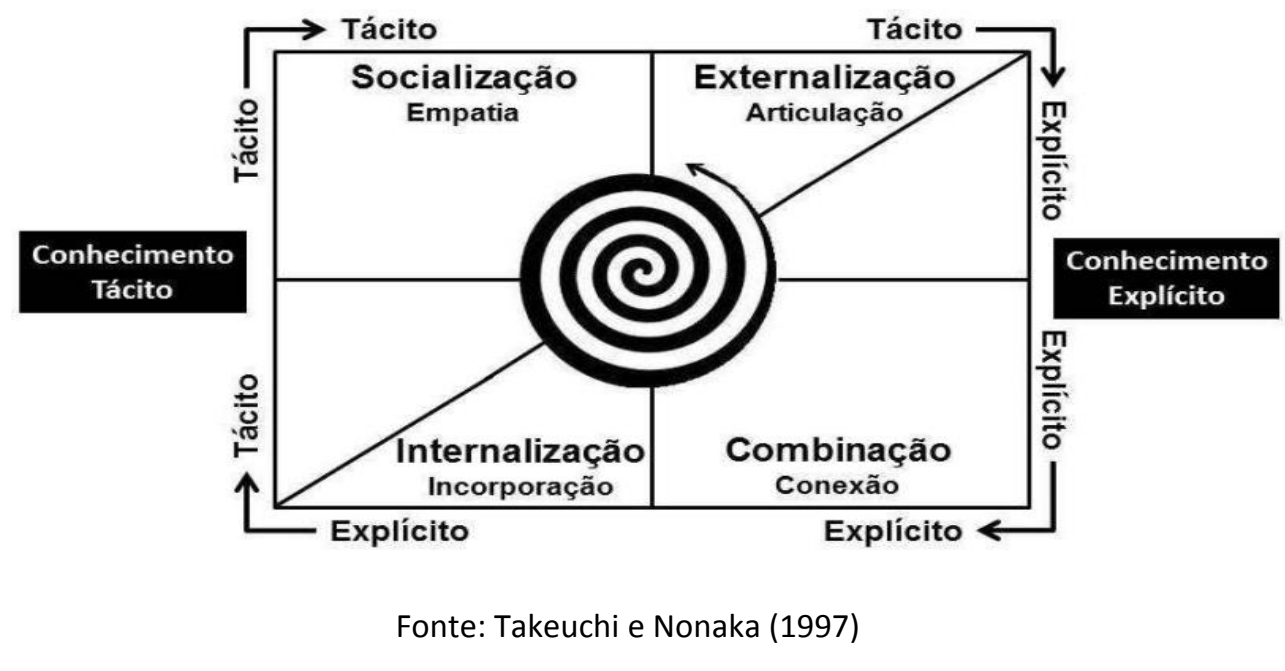

Existem diversas definições para a GC, não havendo um consenso entre os estudiosos da área. Dalkir (2011) considera que seu objetivo básico é alavancar o conhecimento em benefício da organização e se trata, portanto, de uma ferramenta sistemática e deliberada que garante a plena utilização da base do conhecimento da organização, juntamente com o potencial de competências, pensamentos e ideias individuais para criar uma organização mais eficaz.

\subsection{A indústria da moda e os métodos de design}

$\mathrm{Na}$ indústria da moda, de forma geral, o desenvolvimento de coleções conta com a atuação de diversos profissionais, especialmente o designer. Para contextualizar o seu papel, Bonadio (2014) faz um paralelo histórico ao citar a escola Bauhaus, que surge como a primeira escola de design do mundo com o objetivo de formar profissionais que pudessem atender às demandas da época. Com a revolução industrial, evidenciava-se a supervalorização da produção em massa, exigindo valores estéticos, qualidades, funcionalidade e baixo custo. Esse profissional, que trazia o conhecimento de métodos de design, passa a projetar bens de consumo para a indústria pensando no sistema produtivo.

Para Cardoso e Demarchi (2012), a atividade exercida pelo designer de moda considera o entrelaçamento dos conhecimentos e das competências e pode ser considerada como um complexo sistema de conhecimento. Esse sistema de conhecimento busca identificar as 
oportunidades do mercado e aplicá-las nas especificações de um produto, segundo um método aplicado ao projeto, levando em consideração os mais avançados métodos existentes na comunidade acadêmica, nas empresas e nas organizações que atingiram sucesso (MARX; SOARES; BARROS, 2016).

Assim, o percurso percorrido para o desenvolvimento de produtos de moda é composto por métodos projetuais, com vários processos que contemplam etapas, ações, práticas e diversos setores envolvidos, em que um setor abastece o outro com informações, logo, é necessário que estas sejam confiáveis, servindo como subsídio para os designers no desenvolvimento de produtos focados nos clientes. De acordo com Novelli, Moura e Curvello (2013), o uso de métodos voltados para as questões organizacionais torna-se protagonista no desenvolvimento dos produtos com o objetivo de organizar o pensamento criativo.

De acordo com Pazmino (2015), alguns métodos de design são adaptações de outras disciplinas como ciências administrativas, biologia e outras áreas que podem representar extensões das técnicas informais que fazem parte da rotina do designer. Autores como Löbach (2001), Rech (2002), Munari (2002), Montemezzo (2003), Nagano, Stefanovitz e Vick (2014) e Marx, Soares e Barros (2016) sistematizaram o processo de design em diversas etapas e criaram métodos para suportar os diferentes problemas.

\subsection{0 método projetual de design}

Um dos modelos mais comuns e utilizado para o desenvolvimento de produtos de moda no Brasil é o 'método projetual de design', proposto por Montemezzo (2003). O modelo é composto de seis etapas sequenciais, conforme apresenta a Figura 2:

Figura 2 - Etapas do desenvolvimento de produtos de moda

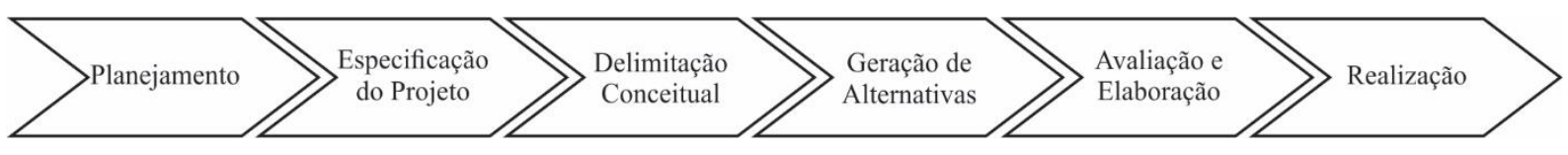

Fonte: Adaptada de Montemezzo (2003)

A primeira etapa, Planejamento, consiste na coleta e análise de informações que dão suporte às decisões que são tomadas no decorrer do processo e que deve contar com a participação dos setores de marketing, projeto e/ou desenvolvimento e, ainda, gerência de produção da empresa. Para que se alcance o bom planejamento a autora propõe as seguintes ações:

- $\quad$ percepção de mercado e descoberta de oportunidades;

- $\quad$ análises/expectativas e histórico comercial da empresa;

- $\quad$ ideias para produto/identificação do problema de design;

- definição de estratégias de marketing, desenvolvimento, produção, distribuição e vendas; e

- definição de cronograma.

Todas essas ações fazem referência ao contexto do mercado, histórico da empresa e à proposta para novos produtos ou coleções e, apesar do designer não realizar essas ações, a sua participação dele é muito importante para que o seu trabalho se inicie com informações que proporcionem maior direcionamento ao começar o processo de desenvolvimento do produto. Isso porque é com base nas informações do mercado e no histórico dos produtos anteriores que se torna possível detectar as necessidades e os desejos dos consumidores, percebendo oportunidades para que possíveis produtos possam ser desenvolvidos e lançados 
no mercado. Tais possibilidades devem ser analisadas sob os critérios da capacidade produtiva e comercial da empresa e devem estar alinhadas ao cronograma de atividades.

A segunda etapa, Especificação do Projeto, ocorre a partir de análises anteriores para delimitar o problema de design, definindo o seu direcionamento mercadológico e mantendo o foco nas necessidades e desejos do consumidor, bem como nas tendências de moda. Ainda nessa etapa definem-se as metas técnicas, funcionais e estéticas do produto a serem desenvolvidas. Igualmente, define-se o dimensionamento da coleção, que representa $o$ número de peças para compor a coleção, distribuídas em uma combinação, um mix, que se refere à variedade de produtos oferecidos por uma empresa em quantidade de peças de acordo com o maior ou menor conteúdo de moda. Essa etapa consiste nas seguintes ações:

- $\quad$ análise e identificação do problema (diretrizes);

- $\quad$ síntese do universo do consumidor (físico e psicológico);

- $\quad$ pesquisa de conteúdo de moda (tendências); e

- $\quad$ delimitação do projeto (objetivos).

Essas ações referem-se à interpretação dos dados coletados com base na análise realizada na etapa Planejamento, a fim de delimitar os objetivos do projeto. Elas também representam um fator importante para as decisões a serem tomadas no decorrer da atividade projetual e fornecem diretrizes para a proposta da coleção com finalidades técnicas e estéticas, conforme a exigência do mercado.

A terceira etapa, Delimitação Conceitual, é baseada nas especificações do projeto. Nela pode-se definir o conceito ou tema geral da coleção que representa os referenciais práticos, estético-simbólicos, funcionais e de estilo, os quais não podem contrariar a imagem da marca e as metas comerciais da empresa. Ainda nessa etapa podem ser delimitados os princípios de estilo, sintetizados em referências de linguagem visual e inseridos naquilo que é normalmente denominado como tema. O tema é o fio condutor de integração e harmonia do conjunto de produtos que são lançados simultaneamente. Nesse contexto, muitas vezes é empregada a elaboração de painéis de imagens que expressam esses referenciais estéticosimbólicos. Essa etapa consiste nas seguintes ações:

- $\quad$ geração de conceitos e definição do conceito gerador; e

- $\quad$ definição de princípios funcionais e de estilo.

Essas ações correspondem à constituição de conceitos, tais como tema de coleção e definições dos princípios funcionais e de estilo que permeiam a coleção.

A quarta etapa, Geração de Alternativas, é caracterizada pelo início da materialização dos referenciais obtidos do conceito gerador de coleção, conforme a etapa anterior, i.e., Delimitação Conceitual. A materialização da proposta ocorre por meio de desenhos e/ou modelagens tridimensionais. O resultado é a transformação da etapa anterior em elementos compositivos para a nova coleção em forma de cores, texturas e elaboração de esboços e modelos. Essa etapa possui as seguintes ações: de modelos); e

geração de alternativas de solução do problema (esboços/desenhos, estudos

- definições de configuração, materiais e tecnologias.

A quinta etapa, Avaliação e Elaboração, é caracterizada pela seleção das melhores alternativas que compõem a coleção a partir das especificações do projeto. Nela são estabelecidas as definições finais da coleção por meio de desenhos técnicos, modelagens e protótipos, para que possa ser testada a usabilidade e, se necessário, realizadas as correções nas peças. Essa etapa representa a seleção das alternativas e definição das configurações técnicas e ergonômicas da coleção. Consiste também em materializar as ideias de projeto e definir as especificações técnicas do produto. As seguintes ações são realizadas nessa etapa:

- $\quad$ seleção das melhores alternativas;

- $\quad$ detalhamento de configuração (desenho técnico); 
- desenvolvimento de ficha técnica, modelagem e protótipo;

- $\quad$ testes ergonômicos e de usabilidade; e

- $\quad$ correções e/ou adequações.

Por fim, a etapa Realização oferece um conjunto de atividades de avaliação, correção e definições finais dos produtos, da sua produção, divulgação e lançamento. Assim, as seguintes ações ocorrem nessa etapa:

- $\quad$ avaliações técnicas e comerciais apuradas;

- $\quad$ correções e adequações;

- $\quad$ graduação da modelagem;

- $\quad$ confecção da ficha técnica definitiva e da peça piloto (aprovação técnica e comercial dos produtos);

- $\quad$ aquisição de matéria-prima e aviamentos;

- $\quad$ orientação dos setores de produção e vendas;

- $\quad$ definição de embalagens e material de divulgação;

- $\quad$ produção; e

- lançamento dos produtos.

Além disso, essa etapa gera os protótipos, efetua os processos produtivos e faz a inserção do produto no mercado.

Montemezzo (2003) destaca que é essencial a atuação do designer em cada uma das etapas do seu modelo de desenvolvimento de produtos de moda. Na etapa de Planejamento o designer não atua de forma direta em nenhuma das ações. Já nas etapas de Especificação do Projeto, Delimitação Conceitual, Geração de Alternativas e Avaliação e Elaboração esse profissional tem um papel ativo em todas as ações. Por sua vez, na etapa de Realização, o designer participa apenas da ação de correções e/ou adequações. Apesar de o designer não ser o responsável pelas demais ações, o seu envolvimento influencia a qualidade e a manutenção do projeto.

A partir das reflexões desse método projetual de design, proposto por Montemezzo especificamente para o desenvolvimento de produtos de moda, observa-se a importância dos aspectos mercadológicos e a proximidade com o público-alvo. Segundo Montemezzo (2003), o designer deve ter contato com a realidade do mercado, com enfoque do projeto no cliente. Esse fator é fundamental para o desenvolvimento do raciocínio projetual de moda, pois as etapas e as ações propostas no método não são rígidas, podendo ser adaptadas à realidade de cada organização.

\subsection{0 ciclo da GC de Meyer e Zack}

O ciclo da GC de Meyer e Zack (1996) é derivado do trabalho sobre a concepção e desenvolvimento de produtos de informação. Esse ciclo sugere que a investigação e o conhecimento sobre design de produtos sejam transferidos para o domínio intelectual e sirvam de base para um ciclo da GC. Ele também consiste na criação de um produto de conhecimento de alto valor agregado em cada fase do processamento de conhecimento. As lições aprendidas com o ciclo físico de produtos podem ser aplicadas à gestão dos ativos de conhecimento.

Todo produto tem uma arquitetura que se refere ao seu conceito de design global. Meyer e Zack (1996) enfatizam a importância de gerir a evolução e a renovação da plataforma de produtos para o sustento do sucesso. As plataformas são as bases para a criação de novas versões derivadas de produtos de forma rápida e eficiente, resultando em diferentes funcionalidades, custo, qualidade e desempenho. Ainda de acordo com os autores, todo produto possui uma arquitetura com potencial para se tornar uma plataforma de produtos. Uma plataforma de produtos serve como base para uma família de produtos. No caso da 
indústria da moda, isso ocorre quando existem produtos básicos 'campeões' de venda. Utilizando-se a mesma modelagem e matérias primas, são incorporados estampas ou bordados de acordo com as tendências de moda, criando assim produtos similares.

A Figura 3 apresenta o fluxo de como criar produtos derivativos a partir do conhecimento do design utilizando uma plataforma de produtos e de processos influenciados por tecnologias e habilidades internas e externas.

Figura 3 - Famílias de produtos e plataformas

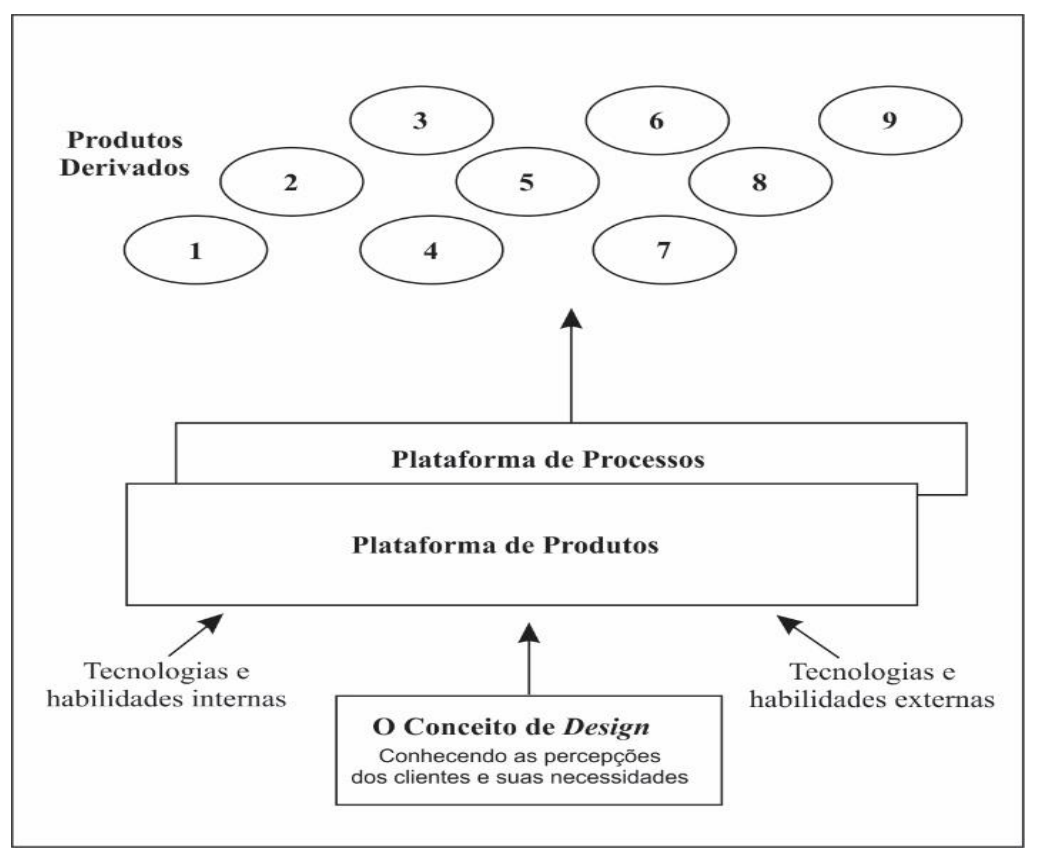

Fonte: Adaptada de Meyer e Zack (1996)

Assim, a plataforma de produtos deve permitir que uma empresa crie novas versões de seus produtos, que evoluem ao longo do tempo por meio da incorporação de novas tecnologias. Isso faz com que a arquitetura se renove constantemente, resultando em um novo design. Por sua vez, a plataforma de processos deve ser composta pelas tecnologias, instalações e processos para a fabricação de produtos, atuando como um facilitador da inovação para a variedade de produtos derivados.

Para gerenciar as informações dos produtos derivados e das famílias de produtos, Meyer e Zack (1996) propõem um framework para a GC denominado de Arquitetura de Informação de Produtos, conforme apresenta a Figura 4.

O framework proposto pelos autores inicia com informações coletadas a partir do fornecedor. Ele contém duas plataformas, a plataforma de produtos (Repositório) e a de processos (Refinaria). A plataforma de produtos é um repositório de dados que gera informações para a criação de famílias de produtos. O Repositório deve ser estruturado para receber conteúdos acerca dos negócios, dos funcionários, das regiões de atuação, dentre outros. O conteúdo desse repositório gera informações como e-mails, boletim de notícias, conteúdo na internet, dentre outros a respeito das famílias de produtos. 
Figura 4 - A arquitetura de produtos de informação

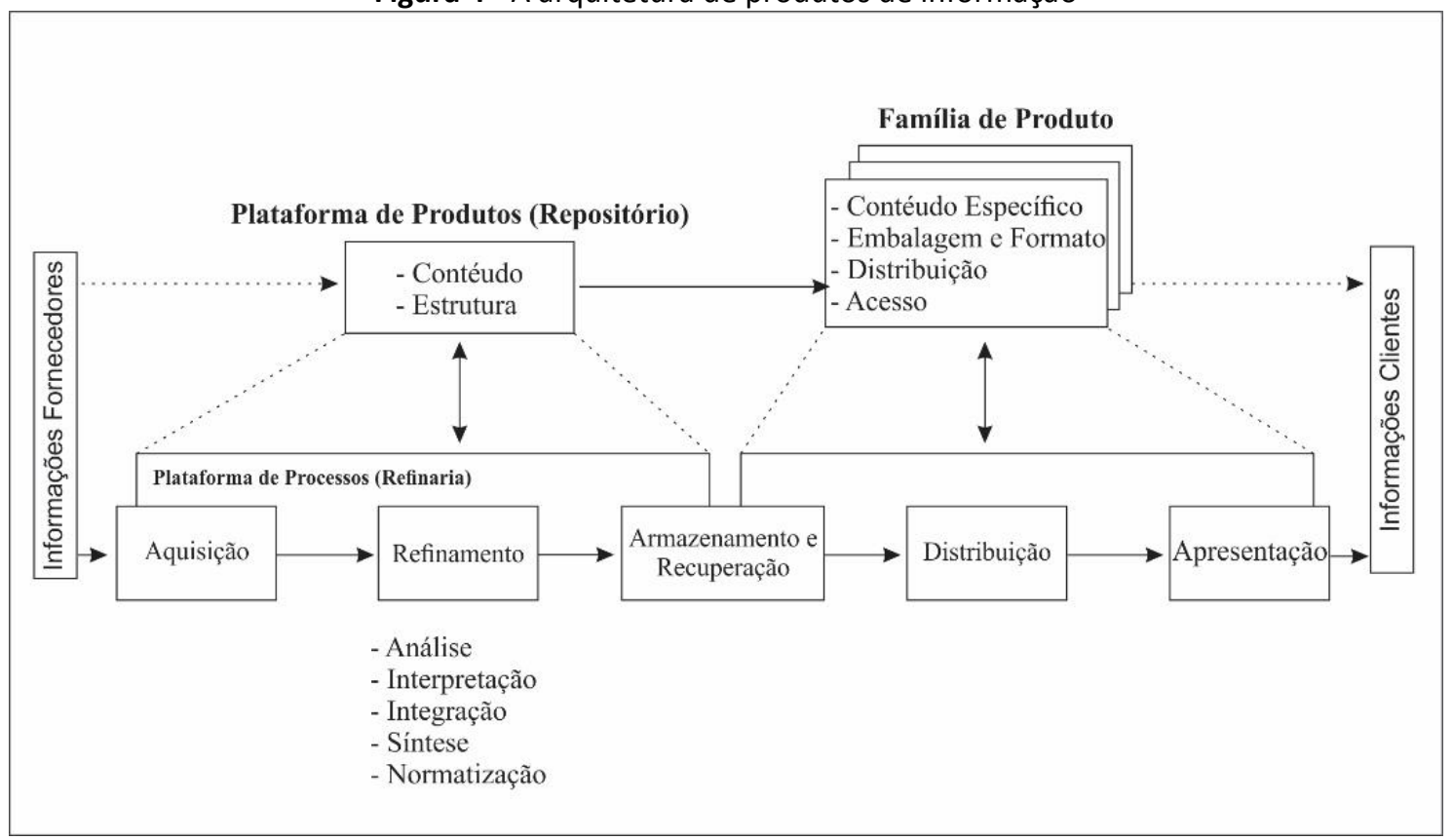

Fonte: Adaptada de Meyer e Zack (1996)

A plataforma de processos, i.e., Refinaria, tem a função de gerenciar e refinar os dados e conteúdos gerados a partir dos dados do fornecedor bem como do Repositório. Essa plataforma é composta por cinco fases de processamento de informação, sendo elas a Aquisição, o Refinamento, o Armazenamento ou Recuperação, a Distribuição e a Apresentação. A Aquisição é a fase responsável pela coleta de dados. Tais são dados coletados em fontes originadas na matéria-prima, qualidade, espaço, largura, profundidade, credibilidade, exatidão, atualidade, relevância, custos, controle, exclusividade, dentre outras. É importante ressaltar que essas fontes de dados devem ser suficientemente confiáveis e consistentes para que esses dados tenham qualidade. Ainda na fase de Aquisição, os autores rementem os termos em Língua Inglesa garbage in e garbage out (i.e., lixo dentro e lixo fora), referindo-se que só devem ser mantidos os dados de alta qualidade, i.e., àqueles que tenham utilidade. É um princípio orientador dessa fase, em que os dados devem ser da mais alta qualidade para a busca de informações de modo a não comprometer a integridade do processo e os produtos finais criados a partir do repositório.

A fase de Refinamento é a principal fonte de valor adicionado, pois refere-se à limpeza ou à padronização dos dados. Essa fase agrega valor por meio da criação de objetos de conhecimento mais prontamente utilizáveis e o armazenamento do conteúdo da forma mais flexível possível para uso futuro. Para que seja armazenado apenas o conhecimento útil para as organizações, o repositório e a refinaria são essenciais para realizar a filtragem do conhecimento.

A fase Armazenamento e Recuperação é uma ponte entre os estágios de Aquisição e Refinamento, que alimentam o repositório, bem como as fases posteriores de geração de produto. $O$ armazenamento pode ser tanto físico (e.g., arquivos, pastas, informações impressas) quanto digital (e.g., banco de dados, software, aplicativos). O Repositório e a Refinaria permitem filtrar o conhecimento e armazenar apenas o conhecimento que tem valor para a empresa. $O$ conteúdo do Repositório deve ser constantemente analisado para alcançar a padronização do conteúdo. O Repositório e a Refinaria precisam ser apoiados por recursos de tecnologia da informação. 
A fase Distribuição refere-se à forma como o produto é entregue ao utilizador final e também de que forma isso ocorre, envolvendo o meio de entrega, tempo, frequência, forma, linguagem, dentre outros. A advertência dessa fase é o meio pelo qual o produto é entregue, como, "dados de áudio devem ter uma maneira de entregar sinais de áudio" (MEYER; ZACK, 1996 , p. 48). O modelo enfatiza ainda a distribuição de conhecimento, principalmente, por meios tecnológicos como o e-mail, por exemplo.

Por fim, a fase Apresentação é onde se realiza a avaliação de todas as fases anteriores. Caso o conteúdo não seja utilizável, significa que o ciclo falhou por não agregar valor ao utilizador e à organização.

Para sustentar a vantagem do produto e evitar sua obsolescência, Meyer e Zack (1996) acreditam que as empresas devem planejar a renovação constante do Repositório e da Refinaria, assim como uma empresa de produtos físicos deve renovar os seus projetos de produtos e processos de fabricação. Renovar uma plataforma de processos requer repensar as tecnologias subjacentes às cinco fases do processo e se esforçar para melhorar e padronizar as interfaces desse processo. Nesse sentido, esse ciclo é caracterizado como 'Refinaria' do conhecimento, i.e., para esses autores a GC não é um acúmulo exaustivo de conteúdo e informações e sim uma seleção dos conhecimentos mais importantes para garantir alta qualidade nos produtos fabricados (DALKIR, 2011).

O modelo de Meyer e Zack, na visão de Dalkir (2011), é uma das descrições mais completas dos elementos-chave envolvidos no modelo da GC. Sua força deriva, principalmente, de seu paradigma abrangente de processamento de informações, que é quase totalmente adaptável ao conteúdo do conhecimento e pode ser adicionado por meio da extração de tendências e reembaladas para prever análises e servir de base para a tomada de decisão por meio da adaptação de produtos para a realidade do público-alvo, organização e região, com o intuito de transformar o conhecimento em ação.

\section{METODOLOGIA}

Esta é uma pesquisa teórica com objetivo exploratório de natureza básica, que utiliza como procedimento uma pesquisa bibliográfica, a qual foi realizada em duas etapas relacionadas às áreas que compreendem esta pesquisa: GC e Indústria da Moda. Foram pesquisados artigos de periódicos e congressos tanto nacionais quanto internacionais. Além disso, foram consultadas teses, dissertações e livros relacionados ao tema. As bases de dados utilizadas para ambas as etapas foram Web of Science, Scopus e Banco de Teses e Dissertações da Coordenação de Pessoal de Nível Superior (BTD/CAPES).

A primeira etapa da pesquisa bibliográfica consistiu em situar o tema em relação à produção científica atualizada de reconhecimento nacional e internacional, considerando-se como critérios recorte temporal a partir do ano de 2005 e palavras-chave em Língua Inglesa, "knowledge management and industrial", "process and fashion industry", "knowledge management and product development and fashion industry" e "knowledge management and product launches and fashion industry", e em Língua Portuguesa, "gestão do conhecimento e processo industrial e indústria da moda"; "gestão do conhecimento e desenvolvimento de produto e indústria da moda" e "gestão do conhecimento e lançamento de produtos e indústria da moda". Essa busca resultou em um total de 39 trabalhos científicos.

O processo de análise dessas publicações envolveu a leitura de títulos e resumos, sendo então selecionadas 17 para a realização da leitura completa. 0 resultado dessa etapa foi a seleção de sete trabalhos, contudo, nenhum deles tratava de um ciclo de GC voltado ou aplicado à indústria da moda. A partir disso, executou-se a segunda etapa da pesquisa bibliográfica tendo em vista identificar pesquisas que tratassem da aplicabilidade do ciclo de Meyer e Zack (1996) na fabricação de produtos que, necessariamente, fossem da indústria da

Perspectivas em Gestão \& Conhecimento, João Pessoa, v. 9, n. 1, p. 154-168, jan./abr. 2019. 
moda. Para essa busca considerou-se o recorte temporal a partir do ano de 2005 e pesquisa em Língua Inglesa com as seguintes palavras-chave: "Meyer and Zack", "knowledge management cycle of Meyer and Zack", "Meyer and Zack cycle e knowledge management and Meyer and Zack". Entretanto a busca não retornou nenhum resultado relevante.

Com a leitura dos trabalhos e as buscas realizadas observou-se que o método projetual de design é muito utilizado na indústria da moda. Tal modelo se originou da síntese das reflexões dos trabalhos de Löbach (2001), Rech (2002), Gomes (2004) e Baxter (2011). Além disso, o ciclo de GC sugerido por Meyer e Zack (1996) mostrou-se altamente alinhado com a indústria da moda, tendo em vista que ele é voltado para a fabricação e lançamento de produtos e famílias de produtos. Portanto, após o estudo aprofundado do ciclo de GC de Meyer e Zack (1996) e do método projetual de design, fez-se um mapeamento das seis etapas propostas no método projetual com as cinco fases apresentadas pelo ciclo de GC de Meyer e Zack. Esse mapeamento estabeleceu a inter-relação entre os modelos, conforme apresenta a próxima seção.

\section{A INTER-RELAÇÃO ENTRE O MÉTOdO PROJETUAL DE DESIGN DE MODA E AS FASES DO CICLO DE MEYER E ZACK}

O método projetual de design de moda de Montemezzo, apresentado na Figura 2, é composto por seis etapas: Planejamento, Especificação do Projeto, Delimitação Conceitual, Geração de Alternativas, Avaliação e Elaboração e Realização. Por sua vez, o framework de GC de Meyer e Zack (Figura 4) contém a plataforma de produtos e a de processos, onde a plataforma de processos é apoiada pelas fases de Aquisição, Refinamento, Armazenamento ou Recuperação, Distribuição e Apresentação. A partir da pesquisa bibliográfica foi possível identificar a inter-relação entre as fases do método projetual de design e as fases do ciclo de Meyer e Zack, apresentadas no Quadro 1.

$\mathrm{Na}$ etapa de Planejamento do método projetual de design, observa-se que as ações de (a) à (d) se inter-relacionam com a fase de Aquisição do ciclo de Meyer e Zack. Isso representa um ponto de partida para toda a atividade projetual de design. A ação (e), que é responsável por definir o cronograma, se inter-relaciona à fase de Refinamento do ciclo da GC de Meyer e Zack porque ela possibilita estabelecer apenas as informações necessárias para a definição do cronograma. Igualmente, essa mesma ação (e) se relaciona à fase de Armazenamento/Recuperação do ciclo da GC, pois o cronograma é um documento que é armazenado de forma física ou digital e, ainda, passível de ser consultado pelos designers durante todo o processo de desenvolvimento de produtos.

$\mathrm{Na}$ etapa Especificação, as ações (a) e (c) estão inter-relacionadas com a fase de Aquisição do ciclo da GC de Meyer e Zack. É por meio delas que o designer identifica o problema de design e inicia a pesquisa de tendências de moda da estação. As ações (b) e (e) estão inter-relacionadas ao Refinamento do ciclo da GC. Essas ações fazem a síntese do universo do consumidor e, por isso, delimitam o projeto por meio da filtragem e limpeza das informações considerando apenas àquelas necessárias para o desenvolvimento dos produtos. Nesse contexto, os conhecimentos são selecionados para facilitar o processo criativo.

$\mathrm{Na}$ etapa Delimitação Conceitual, a ação (a) está inter-relacionada às fases de Aquisição e Refinamento do ciclo da GC de Meyer e Zack, o que representa o ponto de partida da geração de conceitos que direcionaram a coleção. Entretanto, a ação (b) está interrelacionada apenas com a fase de Refinamento do ciclo da GC porque se refere à interpretação, edição e formatação dos conceitos até então gerados, resultando em uma definição que serve como delineamento de visões de projeto.

$\mathrm{Na}$ etapa Geração de Alternativas, a ação (a) está inter-relacionada às fases de Aquisição e Refinamento do ciclo da GC de Meyer e Zack. A inter-relação com a Aquisição se

Perspectivas em Gestão \& Conhecimento, João Pessoa, v. 9, n. 1, p. 154-168, jan./abr. 2019. 
deve pois, simultaneamente, ocorre a pesquisa de conteúdo de moda para a concepção do produto no momento do seu esboço. A inter-relação com o Refinamento ocorre porque as análises e interpretação dos dados e relatórios realizados nas etapas de Planejamento e Delimitação Conceitual são constantemente consultadas como subsídios para a geração de alternativas. A ação(b) dessa mesma etapa se inter-relaciona somente com a fase Refinamento do ciclo da GC. Isso porque as análises e interpretação dos dados e relatórios nas etapas de Planejamento, Delimitação Conceitual e Especificação Projeto, principalmente na ação concernente à pesquisa de conteúdo de moda (tendências), servem como embasamento para decisões relativas aos tecidos e aviamentos, que podem ser utilizados pelos designers no desenvolvimento de novos produtos, refinando assim um conhecimento existente.

$\mathrm{Na}$ etapa de Avaliação e Elaboração as ações (a), (d) e (e) estão inter-relacionadas à fase de Refinamento do ciclo da GC de Meyer e Zack, uma vez que essas ações compreendem a edição e a formatação dos dados em ajustes para que os produtos tenham usabilidade e conforto, refinando assim as suas características. Entretanto, as ações (b) e (c) estão diretamente associadas à fase de Armazenamento/Recuperação do ciclo da GC. Na indústria da moda, o desenho técnico, a ficha técnica, a modelagem e o protótipo são artefatos que estão disponíveis em arquivos armazenados em computadores ou fisicamente. Assim, tais artefatos podem ser considerados repositórios de conhecimento e serem acessados sempre que necessário. Durante o ciclo de vida do produto, o conteúdo do repositório é constantemente analisado para alcançar padronização e possíveis alterações no processo, buscando melhoria contínua dos produtos.

Na etapa Realização do método projetual de design, as ações (a), (b) e (g) estão interrelacionadas à fase de refinamento do ciclo da GC de Meyer e Zack. Assim, o Refinamento deve ser realizado porque no método projetual de design essa é a última possibilidade de realizar melhorias antes do lançamento dos produtos e/ou coleções no mercado. Além disso, é o momento de definir quais embalagens e materiais de divulgação são utilizados. Nessa mesma etapa, ambas as ações (c) e (d) estão inter-relacionadas às fases Armazenamento e Apresentação do ciclo da GC. No que diz respeito ao Armazenamento, essas ações são meios de armazenar o conhecimento dos produtos, sejam eles física ou digitalmente, para posterior acesso. No que diz respeito à Apresentação, ambas as ações produzem as versões finais de modelagem que são utilizadas para a fabricação dos produtos e as fichas técnicas finais que guiam todo o processo produtivo. Ainda na etapa Realização, as ações (e), (h) e (i) estão interrelacionadas à fase Apresentação do ciclo da GC de Meyer e Zack. Essas ações correspondem aos produtos e materiais de divulgação definidos, restando apenas efetuar o pedido do que foi selecionado durante todo o processo de desenvolvimento de produtos para a compra de matérias-primas. A produção deve conhecer os processos a serem executados e o lançamento dos produtos deve estar devidamente planejado.

Quadro 1 - Inter-relação entre o método projetual de design de moda e das fases do ciclo de Meyer e Zack

\begin{tabular}{|l|l|l|}
\hline $\begin{array}{c}\text { Etapas do } \\
\text { método projetual }\end{array}$ & \multicolumn{1}{|c|}{ Ações } & \multicolumn{1}{|c|}{$\begin{array}{c}\text { Fase do ciclo de } \\
\text { Meyer e Zack }\end{array}$} \\
\hline \multirow{5}{*}{ Planejamento } & a) Percepção do mercado e descoberta de oportunidades & \multicolumn{1}{|c|}{ Aquisição } \\
\cline { 2 - 2 } & b) Análises, expectativas e histórico comercial da empresa & \\
\cline { 2 - 3 } & $\begin{array}{l}\text { c) Ideias para produto e/ou identificação do problema de } \\
\text { design }\end{array}$ & $\begin{array}{l}\text { Refinamento e } \\
\text { d) Definição de estratégias de marketing, } \\
\text { desenvolvimento, produção, distribuição e vendas }\end{array}$ \\
\cline { 2 - 3 } & e) Definição do Cronograma & Armazenamento \\
\hline
\end{tabular}

Perspectivas em Gestão \& Conhecimento, João Pessoa, v. 9, n. 1, p. 154-168, jan./abr. 2019. 


\begin{tabular}{|c|c|c|}
\hline \multirow{4}{*}{$\begin{array}{l}\text { Especificação do } \\
\text { projeto }\end{array}$} & $\begin{array}{l}\text { a) Análise e identificação do problema de design } \\
\text { (diretrizes) }\end{array}$ & Aquisição \\
\hline & $\begin{array}{l}\text { b) Síntese do universo do consumidor (físico e } \\
\text { psicológico) }\end{array}$ & Refinamento \\
\hline & c) Pesquisa de conteúdo de moda (tendências) & Aquisição \\
\hline & d) Delimitação do projeto (objetivos) & Refinamento \\
\hline \multirow{2}{*}{$\begin{array}{l}\text { Delimitação } \\
\text { conceitual }\end{array}$} & a) Geração de conceitos e definição de conceito gerador & $\begin{array}{l}\text { Aquisição e } \\
\text { Refinamento }\end{array}$ \\
\hline & b) Definição de princípios funcionais de estilo & Refinamento \\
\hline \multirow[t]{2}{*}{$\begin{array}{l}\text { Geração de } \\
\text { alternativas }\end{array}$} & $\begin{array}{l}\text { a) Geração de alternativas de solução do problema } \\
\text { (esboços, desenhos e estudos de modelos) }\end{array}$ & $\begin{array}{l}\text { Aquisição e } \\
\text { Refinamento }\end{array}$ \\
\hline & b) Definições de configuração e materiais de tecnologias & Refinamento \\
\hline \multirow{5}{*}{$\begin{array}{l}\text { Avaliação e } \\
\text { elaboração }\end{array}$} & a) Seleção das melhores alternativas & Refinamento \\
\hline & b) Detalhamento de configuração (desenho técnico) & \multirow{2}{*}{$\begin{array}{l}\text { Armazenamento/ } \\
\text { Recuperação }\end{array}$} \\
\hline & $\begin{array}{l}\text { c) Desenvolvimento de ficha técnica, modelagem e } \\
\text { protótipo }\end{array}$ & \\
\hline & d) Testes ergonômicos e de usabilidade & \multirow{2}{*}{ Refinamento } \\
\hline & e) Correções e/ou adequações & \\
\hline \multirow{9}{*}{ Realização } & a) Avaliações técnicas e comerciais apuradas & \multirow{2}{*}{ Refinamento } \\
\hline & b) Correções e/ou adequações & \\
\hline & c) Graduação e modelagem & \multirow{2}{*}{$\begin{array}{l}\text { Armazenamento } \\
\text { e Apresentação }\end{array}$} \\
\hline & $\begin{array}{l}\text { d) Confecção de ficha técnica definitiva e peça piloto } \\
\text { (aprovação técnica e comercial dos produtos) }\end{array}$ & \\
\hline & e) Aquisição de matéria-prima e aviamentos & Apresentação \\
\hline & f) Orientação dos setores de produção e venda & Distribuição \\
\hline & g) Definição de embalagens e material de divulgação & Refinamento \\
\hline & h) Produção & \multirow{2}{*}{ Apresentação } \\
\hline & i) Lançamento dos produtos & \\
\hline
\end{tabular}

Fonte: Elaborado pelos autores (2018)

Por sua vez, a ação (f) está inter-relacionada à fase Distribuição do ciclo da GC. Isso significa que o conhecimento em relação aos produtos desenvolvidos é compartilhado com os setores produtivo e de vendas. Para orientação dos setores de produção, o conhecimento é compartilhado por meio de fichas técnicas ou em arquivos armazenados eletronicamente. Assim, toda a cadeia produtiva pode acessar essas informações. No que diz respeito à orientação do setor de vendas, o conhecimento é compartilhado por meio de catálogos dos produtos, convenções para a equipe de vendas e reuniões.

Por meio da inter-relação estabelecida nesta pesquisa, percebe-se que o método projetual de design é um sistema de conhecimento que, alinhado ao ciclo de Meyer e Zack, mostra-se aparelhado de elementos da GC que possibilitam a transferência do conhecimento de design de produtos, a inovação, acompanhando a rápida mudança do mercado fast fashion, e o rápido acesso às informações, por parte dos designers, para o desenvolvimento de produtos alinhados às expectativas dos clientes.

\section{CONCLUSÃO}

Esta pesquisa teve como objetivo estabelecer a inter-relação entre o método projetual de design e o ciclo da GC de Meyer e Zack.

Os resultados demonstraram que o método projetual aplicado ao design, quando utilizado, proporciona um alinhamento com a GC por meio das etapas de Aquisição, 
Refinamento, Armazenamento, Recuperação, Distribuição e Apresentação, alinhadas às suas fases e ações.

Assim, o método projetual de design possibilita à indústria da moda os benefícios da GC, bem como a inovação e a sustentabilidade no mercado porque oferece o dinamismo, a criatividade e a agilidade necessária para o desenvolvimento de produtos de moda, principalmente àqueles relacionados ao fast fashion. Ainda, a inter-relação entre o método projetual e o ciclo da GC de Meyer e Zack sistematiza o conhecimento por toda a cadeia produtiva da moda e permite a reflexão sobre o aprendizado, viabilizando o aprimoramento dos conhecimentos durante as etapas e as ações executadas.

Portanto, este estudo é o ponto de partida para um assunto vasto a ser explorado por pesquisadores da área e a sua contribuição está em demonstrar que o uso do método projetual, como instrumento de GC, gera conhecimento e inovação para as organizações, trazendo vantagens competitivas. Para trabalhos futuros pretende-se avaliar a inter-relação aqui estudada por meio de pesquisa de campo qualitativa com profissionais da área da moda utilizando um protocolo de entrevistas.

\section{REFERÊNCIAS}

ASSOCIAÇÃO BRASILEIRA DA INDÚSTRIA TÊXTIL E DE CONFECÇÃO. Perfil do Setor. [2016]. Disponível em: http://www.abit.org.br/cont/perfil-do-setor. Acesso em: 07 jul. 2017.

BAXTER, M. Projeto de produto: guia prático para o design de novos produtos. 3.ed. São Paulo: Edgard Blücher, 2011.

BONADIO, M. C. A moda no MASP de Pietro Maria Bardi (1947-1987). Anais do Museu Paulista: História e Cultura Material, v. 22, n. 2, p.35-70, 2014.

CARDOSO, M. X.; DEMARCHI, A. P. P. O Processo de Desenvolvimento de Produtos de Moda baseado no Design Thinking: um estudo de caso. Projética Revista Científica de Design, Londrina, v.3, n.2, dez. 2012.

COSTANZO, B. P.; SANCHEZ, L. E. Gestão do conhecimento em empresas de consultoria ambiental. Prod.[online], v.24, n.4, p.742-759, 2014.

DALKIR, K. Knowledge management theory and practice. Boston, MA: MIT Press, 2011.

FREIRE, H. J. F.; DE SOUZA, G. M.; PEREIRA, A. L. O capital intelectual nas organizações públicas. Negócios em projeção, v. 6, n. 1, p. 259-276, 2015.

GOMES, L. V. N. Criatividade: projeto, desenho, produto. Santa Maria: SCHDS, 2004.

LOBACH, B. Design industrial: bases para a configuração dos produtos industriais. São Paulo: Edgard Blücher, 2001.

MARX, R.; SOARES, J. P. R. F.; BARROS, L. Variáveis de contexto organizacional a serem consideradas no projeto de sistemas de recompensas orientados à inovação de produtos. Revista Brasileira de Gestão de Negócios, São Paulo, v. 18, n. 60, p. 267-289, abr./jun. 2016. 
MEYER, M. H.; ZACK, M. H. The design and development of information products. Sloan Management Review, v. 37, p. 43-59, 1996.

MONTEMEZZO, M. C. F. S. Diretrizes metodológicas para o projeto de produtos de moda no âmbito acadêmico. Dissertação (Mestrado em Design) - Universidade Estadual Paulista, Bauru, 2003. $98 p$.

MUNARI, B. Das coisas nascem coisas. São Paulo: Martins Fontes, 2002.

NAGANO, M. S., STEFANOVITZ, J. P., VICK, T. E. Characterization of brazilian industrial companies processes and challenges as to innovation management. Revista Brasileira de Gestão de Negócios, v. 16, n. 51, p.163-179, 2014.

NICHELLE, K. M. Design de moda: a cultura de projeto na moda com base nos conceitos do design estratégico. 2011. 132 f. Dissertação (Mestrado em Design) - Universidade do Vale do Rio dos Sinos, Porto Alegre, 2011.

NONAKA, I.; TAKEUCHI, H. Criação de Conhecimento na Empresa. Rio de Janeiro: Campus, 1997.

NOVELLI, A. L.; MOURA, C. P. de; CURVELLO, J. J. A. ABRAPCORP 2013: teorias e métodos de pesquisa em comunicação organizacional e relações públicas: entre a tradição e a inovação. Dados eletrônicos. Porto Alegre: Edipucrs, 2013. 1110 p.

OLIVEIRA, R. R.; OLIVEIRA, R. R.; LIMA, J. B. de. Reflexão sobre a relação entre a mudança de cultura organizacional e a gestão do conhecimento. Perspectivas em Gestão \& Conhecimento, João Pessoa, v. 6, n. 1, p. 19-35, jan./jun. 2016.

PAZMINO, A. V. Como se cria: 40 métodos para o design de produtos. São Paulo: Blucher, 2015.

RECH, S. R. Moda: por um fio de qualidade. Florianópolis: Udesc, 2002.

TRIERVEILER, H. J.; SELL, D.; PACHECO, R. C. S. A importância do conhecimento organizacional para o processo de inovação no modelo de negócio. Navus - Revista de Gestão e Tecnologia, Florianópolis, v. 5, n. 1, p. 113-126, jan./mar. 2015.

WATSON, M. Z.; YAN, R. An exploratory study of the decision processes of fast versus slow fashion consumers. Journal of Fashion Marketing and Management: an international Journal, v. 17, n. 2, p.p. 141-159, 2013.

Artigo recebido em 25/07/2017 e aceito para publicação em 10/01/2019 